BULLETIN Bulletin hispanique

HISPANIQUE Université Michel de Montaigne Bordeaux

117-1 | 2015

Les poètes des rhéteurs

\title{
La poesía de los historiógrafos
}

\section{Victoria Pineda}

\section{(2) OpenEdition}

\section{Journals}

Edición electrónica

URL: https://journals.openedition.org/bulletinhispanique/3722

DOI: 10.4000/bulletinhispanique.3722

ISSN: 1775-3821

\section{Editor}

Presses universitaires de Bordeaux

\section{Edición impresa}

Fecha de publicación: 1 junio 2015

Paginación: 25-42

ISBN: 979-10-300-0174-7

ISSN: 0007-4640

Referencia electrónica

Victoria Pineda, «La poesía de los historiógrafos», Bulletin hispanique [En línea], 117-1 | 2015, Publicado el 01 junio 2018, consultado el 12 febrero 2022. URL: http://journals.openedition.org/ bulletinhispanique/3722 ; DOI: https://doi.org/10.4000/bulletinhispanique.3722 


\title{
La poesía de los historiógrafos
}

\author{
Victoria Pineda \\ Universidad de Extremadura
}

Parmi les disciplines qui composent ce que Kristeller a appelé le «système des arts» au début des temps modernes, la poésie occupe une position centrale, alors que d'autres savoirs, comme l'histoire, aspirent à se rapprocher de ce centre à la faveur de la théorie rhétorique. Le présent article explore le dialogue institué entre les artes historicae et la poésie et rend compte de l'évolution du rapport de force entre ces deux disciplines.

Mots-clés : historiographie, rhétorique, système des arts, Pedro de Rúa, Fox Morcillo, Cabrera de Córdoba, Jerónimo de San José.

Las disciplinas que componen lo que Kristeller llamó el «sistema de las artes» a comienzos de la Edad Moderna establecieron entre ellas relaciones según las cuales la poesía ocupaba el centro de dicho sistema de manera hegemónica, mientras que los otros saberes -la historia entre ellos- aspiraban a dirigirse a ese centro con la ayuda de la teoría retórica. Este artículo explora el diálogo que los autores españoles de artes historicae establecieron con la poesía para comprobar cuál es el equilibrio de fuerzas que se propone y cómo evolucionó tal equilibrio en el período estudiado.

Palabras claves: historiografía, retórica, sistema de las artes, Pedro de Rúa, Sebastián Fox Morcillo, Luis Cabrera de Córdoba, fray Jerónimo de San José.

The disciplines that compose what Kristeller called the «system of the arts» during the Early Modern period, establish among themselves relationships that placed poetry in the centre of the system, while other arts, including history, try to reach that centre with the aid of the rhetorical theory. This article examines the dialogue that Spanish authors of artes historicae established with poetry, in order to determine how the relationship among the disciplines was proposed and how it developed over time.

Keywords: Historiography, Rhetoric, System of the Arts, Pedro de Rúa, Sebastián Fox Morcillo, Luis Cabrera de Córdoba, fray Jerónimo de San José. 


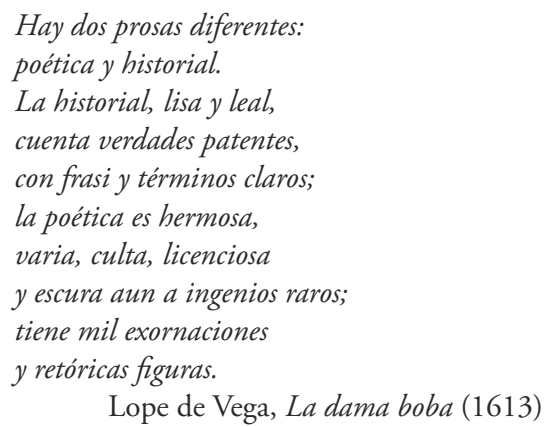

Asi es -replicó Sansón-, pero uno es escribir como poeta, y otro como historiador: el poeta puede contar o cantar las cosas, no como fueron, sino como debian ser; y el historiador las ha de escribir, no como debian ser, sino como fueron, sin añadir ni quitar a la verdad cosa alguna.

Cervantes, Don Quijote de la Mancha II (1615)

Ta cuestión que se debate en este volumen es un examen del canon poético Lespañol de los primeros siglos de la Edad Moderna desde el punto de vista de los rétores del período. Para llevarlo a término sería posible, y quizá útil, encuadrar tal examen en una consideración más general de la relación entre poesía y retórica y también de la relación de ambas con otras disciplinas cercanas en el seno de lo que Kristeller llamó el «sistema de las artes» de la época (1951). Por ello, se me permitirá asomarme al asunto abriendo el gran angular para examinar no ya la canonización de «los poetas de los rétores», sino la manera en que la poesía alimenta a las disciplinas de carácter retórico y simultáneamente se alimenta de ellas. Para explicar la propuesta aclararé a qué me refiero con «disciplinas de carácter retórico».

En la ecuación que planteo tenemos por una parte la poesía, es decir, un arte o actividad que hoy llamaríamos «creativa», y, por otra, la retórica, una disciplina que podemos caracterizar como normativa. El vínculo que nosotros establecemos entre poesía y retórica es un traslado de la relación, que en nuestros días consideramos natural, entre la poética y la retórica, y que, según Kristeller (1951: 501), se remontaría a la proximidad con que en el corpus transmitido de las obras de Aristóteles aparecen los libros Retórica y Poética. Por otro lado, también debemos recordar que en los albores del Renacimiento la palabra "poesía» designaba no solo la producción que he llamado «creativa» sino también la destreza en la interpretación de los poetas antiguos (Kristeller 1951: 510). Pero antes de llegar ahí, y por lo que respecta a la conceptualización teórica de los saberes, la poesía y la elocuencia habían recorrido juntas de la mano los largos siglos medievales, rodeadas, como sabemos, de un grupo de artes que, aunque con ciertas modificaciones, había permanecido bastante 
estable en el tiempo ${ }^{1}$. Tal estabilidad se vería sacudida durante el periodo del humanismo italiano, cuando el peso relativo de las disciplinas en el sistema cultural general sufrió cambios sustanciales:

The Studia humanitatis excluded logic, but added to the traditional grammar and rhetoric, not only history, Greek and moral philosophy, but also made poetry, once a sequel of grammar and rhetoric, the most important member of the whole group [...] Still more characteristic of the Renaissance is the steady rise of painting and the other visual arts (Kristeller 1951: 510, 513).

Para finales del siglo xvi las nociones propuestas por la Poética y la Retórica aristotélicas a través de ediciones, traducciones, comentarios y nuevos tratados surgidos a la sombra de los textos originales de Aristóteles, eran moneda corriente en los círculos intelectuales, y venían a sumarse a las nunca olvidadas pero ahora renovadas ideas procedentes de la retórica latina. Y lo que es más importante: dichas nociones e ideas habían empezado a permear a disciplinas en principio ajenas a la poesía, y muy notablemente a la historia y a las artes visuales. Como ha dicho Lotman (1996: 19), «en la historia de la cultura se pueden distinguir períodos en los que tal o cual arte, hallándose en el punto más alto de su actividad, transmite [...] sus textos a otros sistemas semióticos». Hace décadas que Hanna Gray (1963) ya demostró que «the identifying characteristic of Renaissance humanism» (Gray 1963: 498) fue la búsqueda de la elocuencia: ese fue el lazo que vinculó a los humanistas, por muy diferente que fuera su orientación, en la común ambición de alcanzar un método intelectual válido. La retórica clásica, per se o filtrada a través de sus versiones modernas, constituía la fuente de inspiración de esos anhelos, y no solo por ofrecer temas de reflexión o por servir de base a las posibles aplicaciones prácticas de la elocuencia, sino sobre todo por proporcionar modelos de argumentación y análisis (Gray 1963: 505). La centralidad de las artes del logos a comienzos de la Edad Moderna fue, pues, un fenómeno cultural de decisiva importancia en la conformación del paisaje intelectual de la época. Así, disciplinas nacientes, como la teoría de la pintura, encontraron en la retórica no solo un vocabulario que poder adaptar a sus propias necesidades, sino también unas estructuras con las que poder legitimarse. Y otras disciplinas que sí contaban con raíces antiguas, pero que aspiraban igualmente a desarrollarse en toda plenitud, como la historia (que hasta entonces había sido considerada parte de la gramática, como testimonia Isidoro de Sevilla, Etymologiarum 1.41.2), utilizaron esas doctrinas retóricas para definir su propio objeto y para explicar sus propósitos, sus métodos y sus fines (Gray 1963: 506)².

1. Sobre la idea que acerca de los orígenes de la poesía tenían los hombres del Renacimiento, ver Esteve (2008).

2. Federico Chabod (2006: 18) sugiere que «venuto meno, ormai, l'assillo religioso; svanita quasi completamente la preoccupazione teologico-moralistica, nel clima dell'Umanesimo così preoccupato dei problemi stilistici, della forma, era naturale che, se la storia doveva avere rapporti diretti con altre discipline, li avesse con la poetica». 
Ese es, por tanto, el marco de mi propuesta: un escenario cultural cuyo centro es ocupado indiscutible y hegemónicamente por la poesía, y unas disciplinas en principio periféricas, que pretenden encontrar, al amparo de la teoría retórica, tanto un léxico adecuado con el que expresarse como unos modelos argumentativos eficaces como también una legitimación intelectual e incluso institucional. Dentro de ese marco, entonces, examinaré el diálogo que los tratadistas de la historia establecen con la poesía para comprobar el resultado de dicho diálogo, en el entendimiento de que, como se ha dicho, de la mano de los humanistas surge «una reivindicación de la historia como género independiente y como forma de pensamiento que sirve de complemento o se opone, según el caso, a sus otros dos compañeros de viaje encuadrados en los studia humanitatis, la Filosofía moral y la Poesía» (Jiménez Calvente 2000: 198).

Hablar de la relación entre historia y poesía significa acudir inexcusablemente al famoso pasaje del capítulo IX de la Poética en que Aristóteles propone una nítida distinción entre ellas:

El historiador y el poeta no difieren entre sí por el hecho de que uno escribe en prosa y otro en verso: pues podrían versificarse las obras de Heródoto y no por ello serían menos historia de lo que son. La diferencia radica en el hecho de que uno narra lo que ha ocurrido y el otro lo que ha podido ocurrir. Por ello la poesía es más elevada y filosófica que la historia, pues la poesía canta más bien lo universal, y en cambio la historia lo particular (Aristóteles 1997: 35).

La propagación de las teorías aristotélicas sobre todo a partir de la primera mitad del siglo xvi aseguró la pervivencia de esta rotunda diferenciación y a la vez estimuló el interés por profundizar teóricamente en el arte de la historia, interés que existía ya (Regoliosi 1991: 26), pero que se renovó con fuerza y se tradujo en un incremento notable de la escritura y publicación de tratados historiográficos hasta el ápice que supuso la abundante producción de obras teóricas en la década de los años sesenta (Cotroneo 1971: 24). Los interesados en la materia tenían a su disposición, aparte de este pasaje de Aristóteles y de los comentarios breves que podían encontrar en Cicerón y Quintiliano (a quienes volveré enseguida), pero también en Dionisio de Halicarnaso y algún que otro autor, un único tratado antiguo sobre el arte de la historia: el $D e$ historia conscribenda de Luciano de Samósata. Luciano le dedica varios párrafos al asunto, y en ellos es taxativamente claro. La poesía y la historia son artes gobernadas por reglas diferentes y aun opuestas: en la primera reina la libertad, y la única norma que rige es el deseo del poeta, que compone bajo inspiración; la segunda, asentada sobre la verdad, tiene como fin exclusivo la utilidad, y no el deleite, y en ella no caben ni la ficción ni la adulación (Luciano, 8-10).

Frente a la idea, encarnada por Aristóteles y Luciano, de la historia como disciplina netamente separada de la poesía, el mundo antiguo proporcionaba también otra perspectiva que hacía considerar a la historia no solo como un género cercano a la elocuencia (según leemos en el De oratore ciceroniano), sino como un género en el que «è tollerata, anzi auspicata una peculiare licentia espressiva $[\ldots]$ e perciò una maggiore affinità con il linguaggio denso di 
emozione della poesia» (Regoliosi 1991: 6). Es una perspectiva que Quintiliano expresa con claridad: «Est enim [historia] proxima poetis et quodammodo carmen solutum» (X.1.31).

Algunos de los más importantes textos fundacionales de la historiología moderna recogen ya en el Quattrocento esta tensión de fuerzas centrífugas y centrípetas de la historia con respecto a la poesía. Lo interesante es que, bien para acercarse a ella, bien para superarla, la poesía permanecerá como punto de referencia obligatorio. Mencionaré de manera breve solo tres de estos textos simplemente para dar una idea de los términos en los que se produjo el debate en esos momentos iniciales. El primer texto es el proemio que Lorenzo Valla antepuso a su Historia de Fernando de Aragón, compuesta en 1445, pieza que ha sido considerada «uno dei documenti più interessanti del pensiero umanistico sulla storia e sulla storiografia» (Gaeta 1955: 178). Un breve comentario de Valla al comienzo del escrito parece reflejar la situación predominante y generalizada en la época, en la que el cometido intelectual principal es otorgado a «los filósofos, el segundo en importancia a los poetas, y el tercero y último a los historiadores» (Valla 2002: 73). En su intento de desmontar esa opinión, Valla compara primero a los poetas con los filósofos y demuestra, con criterios de antigüedad, autoridad y ejemplaridad, la preemiencia de aquellos; y luego compara a los historiadores con los poetas y con los filósofos para concluir, con criterios de antigüedad, deleite, utilidad y universalidad, que los historiadores son superiores y «merecen más consideración» que los demás (Valla 2002: 77). El orden de las disciplinas sería, pues, para Valla: historia, poesía, filosofía.

El segundo testimonio es la carta que Guarino da Verona escribió a su discípulo Tobia del Borgo en 1446. Guarino divide con claridad las dos artes, la de la poesía y la de la historia: la una no tiene escrúpulos en pintar caballos alados y en inventar casos inverosímiles, mientras que la otra, "matrona pudica», no osa decir cosas que puedan refutarse, rechazarse o tacharse como mendaces (apud Chabod 2006: 18). En ese pasaje y en realidad en casi toda la carta, Guarino sigue a Luciano, con el consiguiente énfasis en la verdad y en la utilidad como único fin de la historia (Regoliosi 1991: 9), y por eso puede chocar la aparente contradicción entre el cuerpo del texto propiamente dicho y sus primeros párrafos, tomados casi por completo del discurso Pro Archia de Cicerón, y por lo tanto, celebratorios del poder de la poesía y la elocuencia, y por extensión de la historia, discordancia que, a mi juicio, puede ser entendida precisamente como una manifestación de esas tensiones de las que hablé hace un momento.

El tercer y último texto al que aludiré es el único tratado orgánico que gozó de "fuerte notoriedad» (Regoliosi 1991: 4), y el primero en abordar la teoría de la historia de forma sistemática. Me refiero al diálogo Actius que Giovanni Pontano escribió en 1499 , en el que el autor recoge y ordena los conceptos historiográficos que hasta el momento habían formulado los escritores precedentes, según un deseo expreso de «fijar una teoría» historiográfica (Cotroneo 1971: 88). Importa subrayar que el texto de Pontano discurre precisamente en torno a la cuestión de las relaciones entre poesía e historia, y en torno a la argumentación acerca de la superioridad de la primera sobre 
la segunda: la historia vendría a ser, según palabras que remiten directamente al pasaje de Quintiliano que cité antes, una "poetica soluta» (Pontano 1943: 193), y de ahí las importantes páginas que Pontano dedica a la métrica, la armonía y la compositio.

En suma, el problema de las relaciones entre historia, oratoria, retórica y poesía ha sido considerado el tema predominante y caracterizante de la primera etapa de las artes de la historia, etapa que iría desde finales del siglo XIv hasta pasada la mitad del Xvi (Cotroneo 1971: 14). La cuestión irá perdiendo vigencia a medida que la historia vaya adquiriendo la autonomía a la que aspira y vaya siendo contemplada en sí misma o, a lo sumo, en conexión con otros campos diferentes (Cotroneo 1971: 15). Pero a la vez, aun cuando las discusiones sobre la cuestión dejaron de aportar novedades importantes, el debate no dejó de ser esencial para el «sviluppo del pensiero filosofico nell'età moderna» (Cotroneo 1971: 23).

De hecho, como vamos a ver a continuación, el recurso a la poesía y a los poetas seguirá compareciendo en las doctrinas historiográficas incluso hasta bien avanzado el siglo XviI a través de ciertos gestos que revelan no solo una resistencia a olvidar o superar los vínculos «naturales» entre poesía e historia, sino antes al contrario, un deseo de fomentarlos. A fin de ilustrar este proceso he seleccionado las cuatro artes historicae españolas que considero más representativas para la tarea de comprobar qué es la poesía para los historiógrafos, y también, en ciertos casos, para sugerir algunas conclusiones que de ese análisis se derivan y que pueden ser útiles en el examen de los procesos canonizadores de los poetas hispanos. Los cuatro textos fueron escritos por el bachiller Pedro de Rúa (1549), Sebastián Fox Morcillo (1556), Luis Cabrera de Córdoba (1611) y fray Jerónimo de San José (1651).

\section{Pedro de Rúa}

La tercera de las cartas del bachiller Rúa, documento bien conocido para los expertos en Guevara, porque en ella aquel intenta desenmascarar las fabulaciones de este, se había tenido poco en cuenta en los estudios de filosofía de la historia, pero en fecha reciente Karl Kohut (2009: 157) ha llamado la atención sobre ella como "una breve pero sustanciosa teoría de la historiografía».3 Si algo caracteriza el texto es la convicción con que el autor manifiesta sus opiniones. Rúa (1548: 43r-43v) se declara rotundamente partidario de una historia alejada por completo de la poesía:

Ovo también otro género de escriptores que, aunque publicaron sus obras con título de historias, pero puédense llamar fabulosas narraciones más que historias, y ellos, fabuladores o poetas, no historiadores, porque entienden en complacer a los oídos con graciosas maneras de decir y con nuevos o inopinados casos más que con verdaderos hechos. 
Las alusiones a la verdad y al deleite como términos contrapuestos revelan el parentesco de Rúa con la teoría de Luciano, autor que aparece recordado en otros pasajes de la carta. El párrafo que he citado es también una amplificación de la clasificación tripartita de la narratio (narración doctrinal, fabulosa e histórica), que Rúa (1548: 42v) atribuye a Hermógenes, pero que refleja más bien, según creo, el trío historia, fabula, argumentum con que la retórica latina presenta los tipos de narración. ${ }^{4}$ De estas narraciones, dice Rúa, «la doctrinal requiere verdad, [y] la fabulosa ninguna verdad pretende ni verisimilidad, sino solo, so el velo de la fábula, dar algún consejo a los lectores» (ibidem). Pero mezclar fábulas y «verdaderos hechos» es legítimo siempre y cuando se respete lo que la teoría literaria moderna llama el "pacto ficcional»: los autores son «dignos de perdón» cuando «en principio de sus obras piden licencia para escrebir sueltamente, y de lo que escriben ninguna cosa afirman atrevida ni desvergonzadamente» (ibidem), mientras que los que se contentan solo "con mostrarse decidores e inventivos [y] llevan un estruendo en su decir», esos «ni piden crédito de lo que dicen ni lo merecen» (ibidem).

No debemos perder de vista que la finalidad de la carta es el reprochar a fray Antonio de Guevara la inclusión de datos, nombres y hechos «fabulosos» en sus obras «históricas», y que sobre esa base Rúa invita a reflexionar sobre la naturaleza, los fines y el provecho de la historia. Y para todo ello el punto de referencia constante es la poesía. De hecho, todos los fragmentos que acabo de citar sirven para preparar la definición propiamente dicha de la historia, que es introducida con una alusión literal al topos ciceroniano de la historia como testigo de los tiempos, luz de la verdad, vida de la memoria y maestra de la vida (f. 44r). Y todavía, antes de entrar de lleno en materia, Rúa cree necesario describir detalladamente y por vía negativa el procedimiento que deberán seguir los historiadores:

Estos [los falsos historiadores] llevan las palabras medidas por palabras, ponen muy a menudo iguales que respondan a iguales, contrarios a contrarios, semejantes a semejantes; todo su artificio y materia es matizar las palabras, afeitar las sentencias para recrear y mover a los lectores, y no para enseñar verdad, con un estilo más apto para pompa que para pelea; ponen toda su eficacia en el corriente y ruido de la oración, pero, como río de avenida, todo es estruendo de palabras o, más de verdad, como ríos pequeños, que, como llevan poca agua, van dando de piedra en piedra, y al que ha de pasar en noche oscura y no los tiene de antes conocidos, pónenle miedo, pensando que van muy hondos (ff. 43v-44r).

El proceso de escritura que aparece dibujado en estas líneas no es el propio del historiador, sino el del poeta, que cuenta las sílabas, se preocupa por las rimas y busca efectos de simetría. Rúa, como digo, está definiendo a la historia por vía negativa, y el espejo en que se mira no es otro que la poesía. En contraposición, el oficio del historiador, según quedará explicitado en las páginas siguientes, «es evidentemente [el de] mostrar la verdad, adornar los hechos y dichos no

4. Cicerón, De inventione 1.19.27; Rhetorica ad Herennium 1.8; Quintiliano, Institutio Oratoria 2.4.2. 
inventándolos, mas debujándolos o cincelándolos con la buena y distincta narración y disposición, sin curiosa composición de palabras sospechosas de pasión alguna» (f. 45r). La firme oposición entre historia y poesía vertebra de manera teórica y también a través de ejemplos clásicos y bíblicos la mayor parte de la sección doctrinal de la carta, en cuyo diseño afloran las nociones y la terminología de la retórica clásica, fenómeno que, ya lo hemos visto, caracteriza la edad del Humanismo.

La carta es un documento importante además por su fecha de publicación. El pie de imprenta de la primera edición la sitúa en el taller de Juan de Junta de Burgos en 1548. Ese es, a decir de los especialistas en historia de la historiografía, el año en que «le discussioni intorno all'arte storica raggiungono la vera forma del trattato" (citado por Cotroneo 1971: 125). Enrico Maffei, que fue quien escribió estas palabras, no se estaba refiriendo a la carta del bachiller, sino a la Disputatio de historica facultate que Francesco Robortello publicó en Florencia ese 1548. La crítica ha señalado que la fuente principal de la Disputatio es el tratado de Luciano, "che per la prima volta viene ampiamente utilizzato per definire quella che il Robortello chiama appunto la facultas historica» (Cotroneo 1971: 126). Quiero subrayar que, como hemos visto, Luciano es también la fuente de Rúa, así que podemos decir que el texto de la carta es un documento relevante para la historia de la historiografía europea, que tal vez convendría estudiar a la par que el opúsculo de Robortello, teniendo en cuenta cómo ambos definen la historia en confrontación con la poesía y a la vez como forma de la elocuencia 5 .

Pero 1548 es además la fecha de otra publicación que interesa recordar: el tratado In librum Aristotelis de arte poetica explicationes, el primer comentario extenso sobre la Poética de Aristóteles, que el propio Robortello sacó, como la Disputatio, de las prensas ducales de Lorenzo Torrentino. Se ha sugerido que el auge que experimentaría el interés por la teoría de la historia a partir de los años cincuenta y muy notablemente durante los sesenta podría deberse, entre otros motivos, a la atracción que el texto de Robortello habría empezado a ejercer hacia la cuestión de las diferencias entre historia y poesía en su comentario al famoso pasaje del capítulo IX (Cotroneo 1971: 124) ${ }^{6}$. Merece la pena señalar la coincidencia de intereses y de fechas de los escritos de Robortello y Rúa para hacer hincapié en que el trasfondo intelectual en que se van a producir los debates en torno a la historia gravita sobre el concepto de poesía y de poética.

5. Cabría aludir aquí al antecedente que suponen los comentarios que Vives vierte en algunas de sus obras (Veritas fucata I y II, De disciplinis y De arte dicendi), y que contendrían el núcleo de lo que luego desarrollaría Rúa (Kohut 2009: 157), aunque Vives, me parece, se preocupa sobre todo bien por demostrar la mendacidad de los poetas (Veritas fucata) o bien por determinar algunas características de la historia (De arte dicendi), y no tanto por perfilar la especificidad de los historiadores en relación a los poetas.

6. En realidad, doce años antes ya Bernardino Daniello (1536: 41-43) había adaptado las ideas aristotélicas a la poesía en lengua vulgar, y, mezclándolas con las quintilianeas, y en general con la teoría retórica latina, había incluido en su tratado Della poetica unos párrafos sobre la relación entre historia y poesía que pueden considerarse una summa del estado de opinión que habría de prevalecer durante décadas. 


\section{Sebastián Fox Morcillo}

Del 1548 saltamos al 1557, año en que simultáneamente en Amberes (Crisóforo Plantino) y en París (Martin Le Jeune) (aunque parece tratarse de la misma impresión con portadas distintas) se publica el De historiae institutione dialogus de Sebastián Fox Morcillo. Fox, que ha sido considerado «il più acuto trattatista del tempo» (Guido de Ruggiero, apud Cotroneo 1971: 169), escribe la que, por extensión, esfuerzo de sistematización y alcance, puede estimarse como la primera ars historica de la Edad Moderna, «uno dei testi più importanti per il rinnovamento delle idee sulla storia avvenuto nell'età umanisticorinascimentale» (Cotroneo 1971: 172). Las páginas del tratado sugieren una concepción de la historia que va más allá de los acontecimientos militares o políticos para abarcar cualquier experiencia humana, y a la vez sancionan con rotundidad la propuesta de Valla de la utilitas del relato histórico y ahondan en la dimensión moral e incluso política, insinuada por Robortello, de dicho carácter práctico de la historia.

Pero quizá una de las aportaciones más sobresalientes que han distinguido los críticos en el Diálogo sea precisamente la perspectiva que adopta el autor con respecto a las relaciones entre la historia y la poesía por una parte, y entre ambas y la filosofía, por otra. Fox, platónico confeso no solo en esta obra, introduce en el debate historiográfico nociones provenientes de distintos diálogos de Platón, y así, la mención del Crátilo y especialmente de la República ya en las primeras páginas del tratado (Fox Morcillo 1557: 17r-17v), dedicadas a la definición de historia, adelantan la que será la tesis principal de la obra: la condena de los poetas frente a los historiadores y sobre todo frente a los filósofos. El criterio de verdad será el único que Fox acepte para la definición de la historia: puesto que el fin de la historia es la utilidad y no el deleite (idea que Fox toma de Luciano, a quien cita expresamente, f. 25r), el objeto del historiador será solo la verdad, aunque no toda la verdad, porque únicamente hay que narrar «lo grande y lo grave» y no lo «torpe y deshonesto» ${ }^{7}$.

Con todo, el género histórico comparte con el poético algunos elementos: de un lado, los temas, como la descripción de ciudades, la inclusión de causas y decisiones, o la explicación de los preparativos de los hechos; de otro, las técnicas, como el orden de la narración, el qué y el cómo (en lo cual los poetas, sostiene Fox, imitan a los historiadores, f. 41r-41v), o el decoro que debe guardarse en las alocuciones de personajes, en el cual sobresalen, en cambio, los poetas (f. 66r). Pero aunque la historia pueda emplear, igual que la poesía, recursos elocutivos como los epítetos, metáforas, exhortaciones, epifonemas o excursos (f. $77 \mathrm{v}$ ), en realidad es necesario establecer una clara separación de cuatro modalidades diferenciadas que se adaptarán a los distintos asuntos que se tratan: poéticos, filosóficos, cotidianos e históricos. El orden en que se discuten los estilos es importante porque sirve para ańadir la filosofía al

7. «Narranda solum sint magna atque gravia», "sed neque narrari quicquam turpe aut inhonestum» (Fox Morcillo 1557: 22r, 23r). 
debate entre historia y poesía, una tríade semejante a la que Valla proponía en el proemio a la Historia de Fernando de Aragón. Así lo expone Fox:

\begin{abstract}
Nam poesis ad voluptatem et delectationem, non quod verum et rectum, se quod falsum turpeque sit, saepe dicit; philosophica disputatio atque gravis austera est semper, intentosque veluti nervos habet, nec respirare lectorem, aut lectari iu permittit; colloquia negotiis vitae implicata ad res, oratione neglecta, mentem convertunt; historica demum media quodammodo inter poesim ac philosophicum sermonem, gravitatem, moderationem, nervos, sanitatem ab hoc, ab illa venustatem, elationem amoenitatemque habet (ff. 70r-70v) ${ }^{8}$.
\end{abstract}

Y más adelante: «Ergo cum narrationem historicam et gravem esse et iucundam, id est, mediam inter poema, philosophicumque sermonem statutum sit...» (f. $71 \mathrm{v})^{9}$. Esta escala, que sitúa a la historia entre la disciplina superior, la filosofía, y la inferior, la poesía, altera el orden propuesto por Valla: si para este el grado de preeminencia era historia-poesía-filosofía, para Fox es filosofíahistoria-poesía. Nótese que lo que cambia es el lugar de la filosofía, que en uno ocupa el último lugar, y en el otro, el primero, mientras que la pareja historia-poesía permanece estable, con el puesto de honor entre ellas para la historia. Así que, aunque es cierto que, como se ha dicho, la jerarquía propuesta por Fox supone una aportación original al pensamiento historiográfico, sobre todo por el deseo de acercar la historia a la filosofía (Cotroneo 1971: 184), en realidad, ambos, Valla y Fox, comparten el objetivo, común también a los demás historiógrafos de la época, como hemos ya mencionado, de hacer de la historia una disciplina autónoma, separada y superior a la poesía.

Mientras tanto, la poesía es censurada duramente en el tratado de Fox por excitar el placer y los afectos y por no ocuparse de asuntos serios (f. 70v). Y no ya de los asuntos, sino que ni siquiera de la dicción poética debe tomarse nada, ni las palabras ni las figuras, y con ello se evitará que la verdad se vuelva sospechosa (f. 76v). Para que no quepa duda, el diálogo termina con una sección cuyo tema queda identificado en la apostilla impresa marginal como «Contra poetas et eorum studium» (f. 111r), y donde se califica a las fábulas poéticas de «turpissimas» $y$ "pestilentissimas» sobre todo para los jóvenes.

Fox acude a la poesía de Virgilio y Homero para ejemplificar algunos de los recursos de la narración histórica que he mencionado. Además de ellos, el diálogo cita a otros dos autores clásicos, Horacio y Lucano. Frente a esta lista de poetas, más bien exigua, los hablantes del diálogo intercambian nutridos

8. «La poesía dice a menudo, con vistas al placer y al deleite, no lo que es recto y verdadero, sino lo falso y vergonzoso; la disputatio grave y filosófica es siempre austera, mantiene atentos los nervios, por así decirlo, y no permite al lector respirar o deleitarse por mucho tiempo; el [estilo] de las conversaciones, imbricado con los temas de la vida humana, hace que pongamos la mente en el contenido, sin importar la oración; el estilo histórico, finalmente, ocupa un lugar en cierta manera intermedio entre el poético y el filosófico: de este tiene la gravedad, moderación, la fuerza y la pureza; de aquel, el agrado, la amenidad y la elevación» (traducción de Cortijo Ocaña, con modificaciones; en Cortijo Ocańa 2000: 251-252).

9. «Puesto que ha quedado establecido que la narración histórica es grave y agradable, es decir, a medio camino entre el estilo poético y el filosófico...» (Cortijo Ocaña 2000: 252). 
catálogos de historiadores, en elencos que comprenden desde Cadmo y Moisés hasta los indios de América. Pero no nos dejemos engañar: las casi tres decenas de nombres allegados por Fox testimonian, más que un alarde de erudición, la voluntad inequívoca de dotar a la disciplina histórica de un pasado ilustre y de construir de manera retrospectiva un canon que legitime su propia existencia. Se trata de una operación que forma parte, según han advertido los estudiosos de la cultura, y especialmente Iuri Lotman, de los procedimientos mediante los cuales los grupos periféricos intentan abrirse camino hacia el centro en un sistema cultural. Ese esfuerzo de «reconstrucción» va acompañado de «la creación de [...] gramáticas» (Lotman 1996: 17), esto es, de metatextos que, como los que estamos viendo para la historiografía, contribuyen su parte al intento de abandonar la periferia. Otra condición que indica Lotman (1996: 15) para tal empeńo es la de «tomar conciencia de sí mismo», lo cual «significa tomar conciencia de la propia especificidad, de la propia contraposición a otras esferas». Son maniobras que, como se puede comprobar, se aprecian con claridad en el campo que estamos investigando y que, como ha resumido Pozuelo Yvancos (2004: 1-2), «no son ajenas» a la cuestión del canon.

Las herramientas que nos ofrece el modelo de Lotman nos ayudan a explicarnos en un marco teórico general el lento pero constante movimiento del arte de la historia hacia el centro ocupado por la poesía, pero también nos sirven para comprender por qué frecuentemente los tratados cumplen una función primordial incluso cuando su contenido no es más que una repetición de conceptos ya expuestos por autores previos: gracias a la insistencia en esos conceptos, a la repetición, a la multiplicación de los metatextos se consigue avanzar en el camino hacia el centro de la esfera cultural.

\section{Luis Cabrera de Córdoba}

Así que, aunque muchas de las ideas y de los nombres que encontramos en Fox, tanto de los poetas como de los historiadores, se repetirán en el tratado De historia, para entenderla y escribirla que Luis Cabrera de Córdoba publicará en Madrid en 1611, ello no quiere decir que esta obra carezca de importancia. Al contrario, este libro puede considerarse el primer texto significativo de teoría historiográfica escrito en castellano. Estamos a principios del siglo XVII, y aunque, como digo, quizá empiecen a observarse ya incipientes signos de esclerosis por la reiteración de ideas conocidas, la escritura y publicación del tratado testimonian la necesidad de fijar «la importancia de la historia, la del buen historiador, las partes que ha de tener, las de la legítima y perfeta historia, y cómo se hará tal», según rezan los preliminares del libro (f. [ $94 \mathrm{v}]$ ).

El autor dedica el segundo "discurso" a la «antigüedad y origen de la historia», y el tercero, a "la nobleza y estimación de la historia», y por ellos vemos desfilar nuevamente a Moisés, Cadmo y muchos de los nombres citados por Fox. Pero mientras que los hablantes de Fox aducen esos nombres casi en cascada y sin ninguna otra apoyatura, Cabrera se detiene en explicar las 
autoridades que usa en su reconstrucción de los orígenes de la historia, sean antiguas, como Plinio o Laercio, o modernas, como Escalígero o Lipsio, en un camino que conducirá a la crítica de fuentes que acabaría por imponerse en época ilustrada. La alusión a la poesía no llega hasta el discurso cuarto, que versa sobre «las partes y difinición de la historia», y que está dedicado casi por entero a la comparación de las diferencias y semejanzas entre ambas. Partiendo de la definición de la historia como «narración de verdades por hombre sabio para enseñar a bien vivir» (f. 11r), la mención de las «verdades» provoca el comentario sobre la poesía, que «se excluye» porque

es de mentiras, y así es mucha la diferencia y desconveniencia entre la historia y la poesía, no por ser esta en verso, la otra en prosa escrita, como vulgarmente se tiene, si bien el verso es propio de la poética facultad: él no, la imitación sí, hace la poesía, pues la hay en prosa (ibidem).

La evidente filiación aristotélica de este pasaje recorre el capítulo en las explicaciones sobre el tratamiento de varios asuntos. Cuando llega al de la atribución a cada una de las dos artes de lo universal y lo particular, Cabrera enmienda a su fuente y sostiene que «si miramos sola la corteza de las cosas, el poeta a lo particular mira también» (f. 11v), mientras que

el historiador desta manera mira a lo universal, pues todo su fin es enseñar universalmente a bien vivir con los ejemplos, con las oraciones acomodadas a las personas, tiempos, cosas y casos: enseña a decir y hacer, contando la naturaleza de las personas, sus alabanzas, vituperios y otras partes llenas de doctrina civil, con más prudencia que dan los preceptos de los filósofos, pues de la historia sacaron los que dieron (f. 12r).

Cabrera de Córdoba, en la línea iniciada por Valla, a quien sabemos que había leído porque lo cita en este y en otros capítulos del tratado, define a la historia confrontándola y dándole la primacía tanto con respecto a la filosofía, que vendría a depender de ella, como con respecto a la poesía, que deja de ser la única arte universal. Conviene reparar en que el criterio que facilita el adelantamiento de la historia es el de la utilitas, el mismo que Luciano había esgrimido como único legítimo, el que Robortello había sugerido como paso hacia el provecho público y el que Fox había planteado como instrumento del fin político de la historia. La rotundidad con que Cabrera afirma la superioridad de la historia, que enseña con ejemplos, sobre la filosofía, que enseńa por preceptos, refleja un flanco de la argumentación al que se adherirán con aprovechamiento no pocos tratadistas hasta finales del siglo XVII (Pineda 2005), y que acabará por convertirse en uno de los pilares más sólidos sobre los que apoyar la especificidad de la historia.

En consonancia con el deseo de autonomía del arte histórica, Cabrera se cuida de elegir siempre como ejemplos de sus teorías sobre el discurso histórico modelos de la historiografía clásica o moderna, sin cometer nunca el desliz de alegar ejemplos poéticos. Esta manera de proceder cambiará, como veremos, en nuestro próximo teórico, fray Jerónimo de San José. 


\section{Fray Jerónimo de San José}

Fray Jerónimo de San José, Jerónimo Ezquerra de Rozas para el siglo, publicó su Genio de la historia en 1651, obra que ha sido estimada como «el mayor intento teórico que podemos encontrar en Aragón, y tal vez en España, de hacer un tratado dedicado exclusivamente a la historia» (Egido 2000: 173). La primera particularidad que observamos en el libro es la inclusión, entre los abundantes materiales preliminares, de una sección titulada «Autores que tratan de la historia» (f. b3v) y que no es otra cosa que un recorrido diacrónico por los metatextos historiográficos, desde Luciano de Samósata hasta Luis Cabrera de Córdoba. El paso es importante, porque reconoce no ya la existencia de la historia como arte independiente, que eso a estas alturas, como veremos, parece darse por descontado, sino porque ratifica que se han producido las condiciones que facilitan el avance desde la periferia hacia el centro.

Tras unos primeros capítulos en los que se amplifica el punto de partida del libro, es decir, la utilidad y provecho de la historia, se pasa a una sección sobre su «dignidad y excelencia», y en ella se sitúa a la historia en una posición de sobrada ventaja sobre las

otras artes y facultades, que mendigan della mucho más de lo que más las enriquece y ennoblece: porque la pintura, escultura y arquitectura, para el retrato y representación de las cosas que imitan, se valen de la relación de ellas mismas; la poesía, si finge, es sobre algún suceso verdadero, y si no finge, sustancialmente es historia, aunque poetizada; la filosofía moral, la retórica, la jurisprudencia, la ética, económica, física y política no pueden dar un paso sin el socorro de la historia; y aun la sagrada teología [...] apoya también sus verdades con el testimonio y experiencias referidas en ella (p. 23).

Varios elementos llaman la atención en este pasaje: primero, la inclusión en la lista de «artes y facultades» de nuevas y variadas disciplinas consideradas en condición de igualdad con las clásicas y antiguas; segundo, la preferencia que se otorga a la pintura, escultura y arquitectura, que parecen haber entrado definitivamente en el «sistema de las artes» descrito por Kristeller, y que aquí aparecen en primer lugar; y tercero, la consideración de la poesía sin ninguna distinción especial con respecto a las demás, a diferencia de la teología, que sí aparece singularizada. Estamos ante un panorama distinto al que veíamos unas décadas más atrás, en el que, tal y como se demostrará a lo largo del tratado, la poesía ha perdido en parte -no totalmente- su función de pivote sobre el que giran las artes de la palabra. Paradójicamente, al no ser percibida como una disciplina contra la que hay que definirse, la poesía es invocada con una naturalidad que resulta ciertamente insólita. Así, por ejemplo, al declarar la esencia de la historia, San José explica que "el género es la narración, que conviene también a la del poeta, orador y fabulista, los cuales narran en sus poemas, oraciones y fábulas», aunque es verdad que a continuación aclara que la diferencia estriba en que la historia debe ser «escrita, llana y verdadera» (p. 58), siendo las dos últimas características las que distinguen a la historia 
de la poesía. O cuando trata de las descripciones, el autor no tiene reparo en constatar que «se hallan en los mejores historiadores unos trozos de prosa bellísima $[\ldots]$ que cogen entre manos, emulando tal vez, y aun escediendo, a los poetas» (p. 76), ni tampoco tiene inconveniente en recomendar como modelos de descripción, junto con historiadores y oradores, a los poetas, por ser los que "con más gala [las] ejecutaron", y así «en Virgilio, Horacio, Lucano, Marcial y otros desta clase y esfera hallará el que desea escribir con hermosura y perfección ejemplos ilustrísimos» (p. 77). O cuando menciona los preceptos horacianos de la utilidad y la dulzura, afirma que estos son necesarios «no solo para el poeta [...], sino también para el orador e historiador, y para cualquier otro que escribe en cualquier materia» (p. 240), noción que ilustra con traducciones al castellano de textos de Marcial y con una paráfrasis poética, también en castellano, de los Salmos.

Los comentarios sobre las diferencias de las artes aparecen, como sería de esperar, en la sección donde se examina el estilo específico del historiador: a la historia le corresponde, tal como había sostenido también Fox Morcillo, el estilo mediano, que participa del «supremo», que es el usado para "asuntos heroicos y divinos» (p. 103) en prosa o en verso, y del «ínfimo», que es "a propósito para tratados y discursos de prosa o verso familiar [...] y también para aquella parte de la poesía que pertenece a lo cómico y jocoso» (p. 103) ${ }^{10}$. Esa concatenación de los tres estilos, que se determinan de alguna manera entre sí, le sirve a fray Jerónimo para, en un sugestivo giro, encarecer la dificultad de alcanzar un buen estilo histórico por el encumbramiento a que ha llegado «el estilo poético y retórico» en España: siendo que «han levantado nuestros españoles tanto el estilo, que casi han igualado con el valor la elocuencia, como emparejado las letras con las armas», "¿qué medianía le puede quedar [a la historia] que no parezca, y sea, estremo?» (p. 107). Los lectores se han acostumbrado de tal modo a los artificios -se lamenta el carmelita- que son pocos los que no buscan y admiran el "crujiente y campanudo horror de voces» (p. 109) a que ha llegado la poesía española ${ }^{11}$. Aurora Egido (2000: 172) ha indicado el parentesco de estas ideas con otras semejantes que vierte Baltasar Gracián en el Arte de Ingenio, y que ambos habrían quizá aprendido en Bartolomé Leonardo de Argensola.

Pero dejando aparte el diagnóstico que a fray Jerónimo le merece el panorama poético patrio, lo significativo para nosotros es cómo enlaza sin reserva ninguna el ámbito de la escritura histórica con el de la poesía, algo que no habíamos visto en los autores precedentes. Yendo a lo específico, San José examina «la novedad de estilo» (p. 111) para deslindar los excesos reprensibles de las aportaciones positivas. Entre estas últimas, el ejemplo que le parece paradigmático es el de Garcilaso de la Vega, cuya elegancia «ayer se tuvo por osadía poética [y] hoy es prosa vulgar» (p. 113). Autoriza su opinión con las estrofas que Horacio le dedica al neologismo en el Ars poetica (vv. 70ss.) traducidas en verso castellano,

10. Para el estudio de una versificación de estas ideas por parte del propio carmelita, ver Egido (2000: 175).

11. Sobre «la decadencia de la poesía castellana», véase Rico García (2005: 158-162). 
y que, por cierto, son las mismas (en traducción diferente) que había usado Cascales en las Tablas poéticas y las que habían circulado en medio de las polémicas gongorinas (Roses Lozano 1994: 163).

El Genio de la historia ofrece, en efecto, ejemplos poéticos, y nada menos que de poetas españoles contemporáneos, como modelos para el lenguaje histórico. Esta inclusión de fragmentos poéticos modernos en español o de clásicos traducidos (sobre todo Marcial, el «bilbilitano poeta»; ver Marina Sáez 2009) es otro de los rasgos particulares de la obra. Se trata de un recurso al que acude el autor "por suavizar algo lo serio y preceptivo desta prosa» (p. 113), y merece que nos detengamos en él porque da idea de hasta qué punto fray Jerónimo considera innecesario ahondar en la distancia entre historia y poesía. Así también, en el capítulo dedicado a dilucidar «hasta dónde se podrá levantar lícitamente el estilo»(p. 124), donde se dice explícitamente que el estilo «supremo» no es el propio del historiador, fray Jerónimo se ve, sin embargo, en la obligación de declarar «en qué manera, cuándo y a quién sea lícito y aun obligatorio sublimar el lenguaje», "por la afinidad que con él tiene», y para ello trae unos tercetos de Bartolomé Leonardo de Argensola sacados de la epístola a Fernando de Soria, que le sirven como demostración de que el «subir del estilo ha de ser en ciertos grados, y con tal arte y temple, hurtándose al ordinario y vulgar modo de hablar y escribir, que no parezca ignorar y desquiciar el arte, sino engrandecerla y mejorarla» (pp. 125-126; véase Cacho Palomar 2000).

Bartolomé y su hermano Lupercio vuelven a comparecer en la sección dedicada a la claridad de los vocablos, todavía dentro de la discusión sobre la «novedad», en la que fray Jerónimo sostiene que no hay inconveniente en usar palabras extrańas siempre que se coloquen de tal manera que ellas mismas manifiesten «su propia significación» (p. 160), pero que han sido pocos los escritores que han llegado a alcanzar esa facultad, aunque quien sí «la estimó y alcanzó con singular destreza fue aquel milagroso par de ingenios en todo hermanos» (p. 160). Y Bartolomé se cita nuevamente, con nada menos que once tercetos, en la defensa de la parsimonia que debe presidir la tarea del escritor. Es evidente que la presencia destacada de autores aragoneses no es casual, sino que forma parte de una estrategia perfectamente planificada (Egido 2000: 171), y que tendría un paralelo en otros cánones de tipo localista, como ha estudiado Escobar Borrego (2005), pero ahora importa resaltar, más que ese detalle, el resultado que produce tal imbricación de figuras poéticas en un tratado historiográfico.

A decir verdad, al leer las páginas de la obra uno puede tener la impresión de que por momentos el autor ha olvidado que su argumento principal es la técnica histórica, y de que está componiendo un tratado híbrido en que se han superpuesto el arte poética y el arte histórica (Cacho Palomar 2000). De hecho, el propio fray Jerónimo comenta en una captatio benevolentiae epilogal que «no es fácil escribir un libro que trate del modo de escribir libros» (p. 321), y que de todas formas,

en su Arte poética Horacio, y en sus Instituciones retóricas Cicerón y Quintiliano, con la ocasión de la poesía y la retórica, enseñaron a todo género de escritor el arte de 
escribir, y el parentesco desta nuestra materia con otras admite, y aun pide, que para todas se adviertan documentos generales (p. 320).

Teniendo en cuenta la trayectoria que hemos resumido desde la carta de Pedro de Rúa hasta este Genio de la historia, no cabe duda de que el tratado de fray Jerónimo de San José evidencia unas actitudes muy particulares y muy alejadas ya de aquellos deseos de determinar y detallar las especificidades del género histórico. Con todo, es innegable que la poesía, en unos vista en su disparidad, en otros, en su cercanía con respecto a la historia, constituyó durante dos siglos un fulcro inexcusable en la relación de fuerzas de los saberes altomodernos.

\section{Bibliografía}

Aristóteles, Poética, trad. José Alsina Clota, Barcelona, Icaria, 1997.

Burke, Peter, «History, Myth, and Fiction: Doubts and Debates», en José Rabasa, Masayuki Sato, Edoardo Tortarolo y Daniel Woolf, eds., The Oxford History of Historical Writing, vol. 3 (1400-1800), Oxford, Oxford University Press, 2012, pp. 261-281.

Cabrera de Córdoba, Luis, De historia, para entenderla y escribirla, Madrid, Luis Sánchez, 1611.

Cacho Palomar, María Teresa, "Una poética para una escuela: el Genio de la historia», en José Enrique Laplana, ed., Actas del I y II Curso en torno a Lastanosa: La cultura del Barroco / Los jardines: arquitectura, simbolismo y literatura, Huesca, Instituto de Estudios Altoaragoneses, 2000, pp. 15-27.

Carrillo de Sotomayor, Luis, Obras, 2a ed. Madrid, Luis Sánchez, 1613.

Chabod, Federico, Lezioni di metodo storico, ed. Luigi Firpo, $3^{\mathrm{a}}$ ed., Bari, Laterza, 2006.

Cortijo Ocańa, Antonio, Teoría de la historia y teoría politica en Sebastián Fox Morcillo. "De historiae institutione dialogus». "Diálogo de la enseñanza de la historia», Alcalá de Henares, Universidad de Alcalá, 2000.

Cotroneo, Girolamo, I trattatisti dell" «ars historica», Nápoles, Giannini Editore, 1971.

Daniello, Bernardino, Della poetica, Venecia, per Giovan' Antonio di Nicolini da Sabio, 1536.

Egido, Aurora, Las caras de la prudencia y Baltasar Gracián, Madrid, Castalia, 2000.

Escobar Borrego, Francisco Javier, «Los procesos de canonización en la preceptiva literaria renacentista», en Begońa López Bueno, dir., En torno al canon: aproximaciones y estrategias, Sevilla, Universidad de Sevilla, 2005, pp. 97-139.

Esteve, Cesc, «Epicus pater historiarum. La poesia èpica en la teoria de la història del Renaixement", en Lara Vilà, ed., Estudios sobre la tradición épica occidental (Edad Media y Renacimiento), Madrid y Bellaterra, Universitat Autònoma de Barcelona, Universidad Carlos III de Madrid y Editorial Caronte, 2011, pp. 109-121. 
Esteve, Cesc, La invenció dels orígens. La història literària en la poètica del Renaixement, Barcelona, Publicacions de l'Abadia de Montserrat, 2008.

Fox Morcillo, Sebastián, De historiae institutione dialogus, Amberes, apud Christophorum Plantinum, 1557.

Gaeta, Franco, Lorenzo Valla: Filologia e storia nell'umanesimo italiano, Nápoles, Istituto Italiano per gli Studi Storici, 1955.

Gray, Hanna H., «Renaissance Humanism: The Pursuit of Eloquence», Journal of the History of Ideas 24.4 (1963) 497-514.

Holanda, Francisco de, De la pintura antigua, seguido de "El diálogo de la Pintura», prólogo de Elías Tormo, edición y notas Francisco Javier Sánchez Cantón [1921], edición facsímil, Madrid, Visor, 2003.

Jerónimo de San José, Genio de la historia, Zaragoza, Diego Dormer, 1651.

Jiménez Calvente, Teresa "Teoría historiográfica a comienzos del siglo XVI», en Alfredo Alvar Ezquerra, ed., Imágenes históricas de Felipe II, Alcalá de Henares, Centro de Estudios Cervantinos, 2000, pp. 197-216.

Kohut, Karl, «Las primeras crónicas de Indias y la teoría historiográfica», Colonial Latin American Review 18.2 (2009) 153-187.

Kristeller, Paul Oskar, "The Modern System of the Arts: A Study in the History of Aesthetics», Journal of the History of Ideas 12.4 (1951) 496-527.

Lee, Rensselaer W., Ut pictura poesis. La teoría humanistica de la pintura, trad. Consuelo Luca de Tena, Madrid, Cátedra, 1982.

Lotman, Iuri M., "Acerca de la semiosfera», en La semiofera I: Semiótica de la cultura y del texto, trad. Desiderio Navarro, Valencia, Universidad de Valencia, 1996, pp. 1025 .

Luciano de Samósata, How to Write History, en Lucian IV, ed. y trad. K. Kilburn, Loeb Classical Library, Cambridge, MA, Harvard University Press, 1959.

Marina Sáez, Rosa María, «Epigramas de Marcial en el Genio de la historia de Fray Jerónimo de San José», en José María Maestre Maestre, Joaquín Pascual Barea y Luis Charlo Brea, eds., Humanismo y pervivencia del mundo clásico. Homenaje al profesor Antonio Prieto, vol IV.3, Alcañiz y Madrid, Instituto de Estudios Humanísticos y Consejo Superior de Investigaciones Científicas, 2009, pp. 1277-1288.

Nelson, William, Fact or Fiction: The Dilemma of the Renaissance Storyteller, Cambridge, MA, Harvard University Press, 1973.

Pineda, Victoria, «La tradición del exemplum en el discurso historiográfico y político de la España imperial», Revista de literatura 67.133 (2005) 31-48.

Pineda, Victoria, «De la retórica a la teoría artística: el lenguaje de la descripción», en Nuria Rodríguez Ortega y Miguel Taín Guzmán, eds., Teoría y literatura artística en España (siglos XVI, XVII y XVIII), (en prensa).

Pontano, Giovanni, I dialoghi, ed. Carmelo Previtera, Florencia, Sansoni, 1943.

Pozuelo Yvancos, José María, «I. Lotman y el canon literario», Entretextos. Revista Electrónica Semestral de Estudios de Semiótica 3 (2004) 1-12 <http://www.ugr. es/ - mcaceres/entretextos.htm>. 
Regoliosi, Mariangela, "Riflessioni umanistiche sullo "scrivere storia" , Rinascimento 31 (1991) 3-37.

Rico García, José Manuel, «Algunas consideraciones sobre los procesos de canonización en la preceptiva literaria. Siglo XVII", en Begońa López Bueno, dir., En torno al canon: aproximaciones y estrategias, Sevilla, Universidad de Sevilla, 2005, pp. 141-166.

Roses Lozano, Joaquín, Una poética de la oscuridad. La recepción critica de las Soledades en el siglo XVII, Londres y Madrid, Tamesis, 1994.

Rúa, Pedro de, Cartas de Rhúa, lector en Soria, sobre las obras del Reverendísimo señor Obispo de Mondoñedo, Burgos, Juan de Junta, 1549.

Valla, Lorenzo, Historia de Fernando de Aragón, trad. Santiago López Moreda, Madrid, Akal, 2002.

Vilanova, Antonio, «Preceptistas espańoles de los siglos XVI y XVII», en Guillermo Díaz Plaja, dir., Historia general de las literaturas hispánicas, vol. III, Barcelona, Vergara, 1969, pp. 565-692. 